\title{
Mechanistic Complexity of Asymmetric Transfer Hydrogenation with Simple Mn-Diamine Catalysts
}

\author{
Robbert van Putten, ${ }^{\dagger}$ Georgy A. Filonenko, ${ }^{\dagger \odot}$ Angela Gonzalez de Castro, ${ }^{\ddagger}$ Chong Liu, ${ }^{\dagger, \perp}$ \\ Manuela Weber, ${ }^{\S}$ Christian Müller, ${ }^{\S}$ Laurent Lefort, ${ }^{\ddagger} \odot$ and Evgeny Pidko, ${ }^{*},, \| \odot$ \\ ${ }^{\dagger}$ Inorganic Systems Engineering Group, Department of Chemical Engineering, Faculty of Applied Sciences, Delft University of \\ Technology, Van der Maasweg 9, 2629 HZ, Delft, The Netherlands \\ ${ }^{\ddagger}$ InnoSyn B.V, Urmonderbaan 22, 6167 RD, Geleen, The Netherlands \\ ${ }^{\S}$ Freie Universität Berlin, Institute of Chemistry and Biochemistry, Fabeckstrasse 34/36, D-14195 Berlin, Germany \\ "TheoMAT Group, ChemBio Cluster, ITMO University, Lomonosova str. 9, Saint Petersburg, 191002, Russian Federation
}

Supporting Information

ABSTRACT: The catalytic asymmetric transfer hydrogenation (ATH) of ketones is a powerful methodology for the practical and efficient installation of chiral centers. Herein, we describe the synthesis, characterization, and catalytic application of a series of manganese complexes bearing simple chiral diamine ligands. We performed an extensive experimental and computational mechanistic study and present the first detailed experimental kinetic study of Mn-catalyzed ATH. We demonstrate that conventional mechanistic approaches toward catalyst optimization fail and how apparently different precatalysts lead to identical intermediates and thus catalytic performance. Ultimately, the $\mathrm{Mn}-\mathrm{N}, \mathrm{N}$ complexes under study

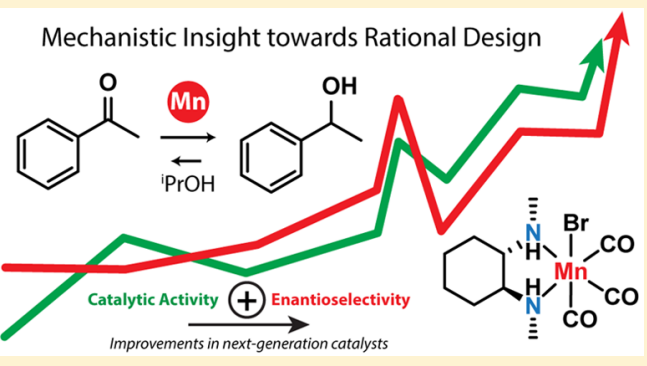
enable quantitative ATH of acetophenones to the corresponding chiral alcohols with $75-87 \%$ ee.

\section{INTRODUCTION}

Homogeneous hydrogenation catalysis with earth-abundant $3 \mathrm{~d}$ transition metals (TMs) such as $\mathrm{Fe}$, Co, and Mn has received remarkable attention from the catalytic community in recent years as a benign and sustainable alternative to processes involving noble metals. ${ }^{1,2}$ This increased focus has led to the rapid development of highly potent first-row transition metal catalysts for a vast number of transformations involving hydrogen-transfer steps, such as hydrogenations, dehydrogenations, and coupling reactions. ${ }^{3-7}$ While $\mathrm{Ru}$ and Ir remain the conventional metals for these reactions, ${ }^{8}$ several examples have emerged of early TMs matching or even surpassing the catalytic activity of noble metals, highlighting the vast chemical potential of this class of homogeneous catalysts. ${ }^{9-12}$

In addition, first-row TM catalysts exhibit striking reactivity patterns unprecedented in hydrogenation catalysis. ${ }^{3,5,13,14} \mathrm{~A}$ chemically distinct feature of some manganese hydrogenation catalysts is that they do not rely on commonly employed strong donor ligands such as phosphines. ${ }^{15,16}$ Indeed, for Mn, the introduction of simple bi- or tridentate nitrogen-donor ligands was sufficient to promote hydrogenation of carbon dioxide to formate and formamide ${ }^{17}$ and transfer hydrogenation of $\mathrm{C}=\mathrm{X}$ bonds $(\mathrm{X}=\mathrm{O}, \mathrm{N})$, e.g., ketones, imines, and aldimines. $^{18-25}$

In order to understand the origin of catalytic activity and causes for the current limitations of Mn systems, we carried out a detailed mechanistic and kinetic study of Mn catalysts in the asymmetric transfer hydrogenation of ketones. The groups of Kirchner, ${ }^{26}$ Clarke, $^{27}$ Beller, ${ }^{28,29}$ and Morris ${ }^{30}$ reported the use of Mn catalysts bearing multidentate phosphine ligands for the asymmetric hydrogenation of ketones. However, we decided to focus on simpler diamine-based Mn catalysts, as were reported by Sortais and co-workers. ${ }^{31}$ From a practical and cost point of view, we deemed these catalysts attractive candidates for industrial applications, ${ }^{32,33}$ as the active system could be generated in situ and was shown to achieve the ATH of a large scope of aryl ketones. After an extensive screening of (chiral) diamines, the combination of $1 \mathrm{~mol} \% \mathrm{Mn}(\mathrm{CO})_{5} \mathrm{Br}$ and ligand $(\mathbf{1 R}, 2 \mathrm{R})-\mathbf{N}, \mathrm{N}^{\prime}-\mathrm{Me}_{2}$-DPEN was identified as the most potent, ultimately enabling good to quantitative yields of corresponding alcohols with 30-90\% enantiomeric excess (ee) (Scheme 1).

Scheme 1. Chiral Mn-N,N Catalysts for Asymmetric Transfer Hydrogenation of Ketones

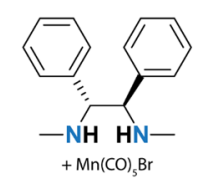

$(1 R, 2 R)-N, N^{\prime}-\mathrm{Me}_{2}-\mathrm{DPEN}$

Sortais ${ }^{31}$

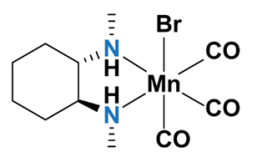

$(1 \mathrm{~S}, 2 \mathrm{~S})-N, N^{\prime}-\mathrm{Me}_{2}-\mathrm{DACH}$

This work
Received: July 4, 2019

Published: August 15, 2019 
Scheme 2. Screening of In-Situ Manganese-N,N and Manganese-P,N Catalysts for Asymmetric Transfer Hydrogenation of Acetophenone ${ }^{a}$

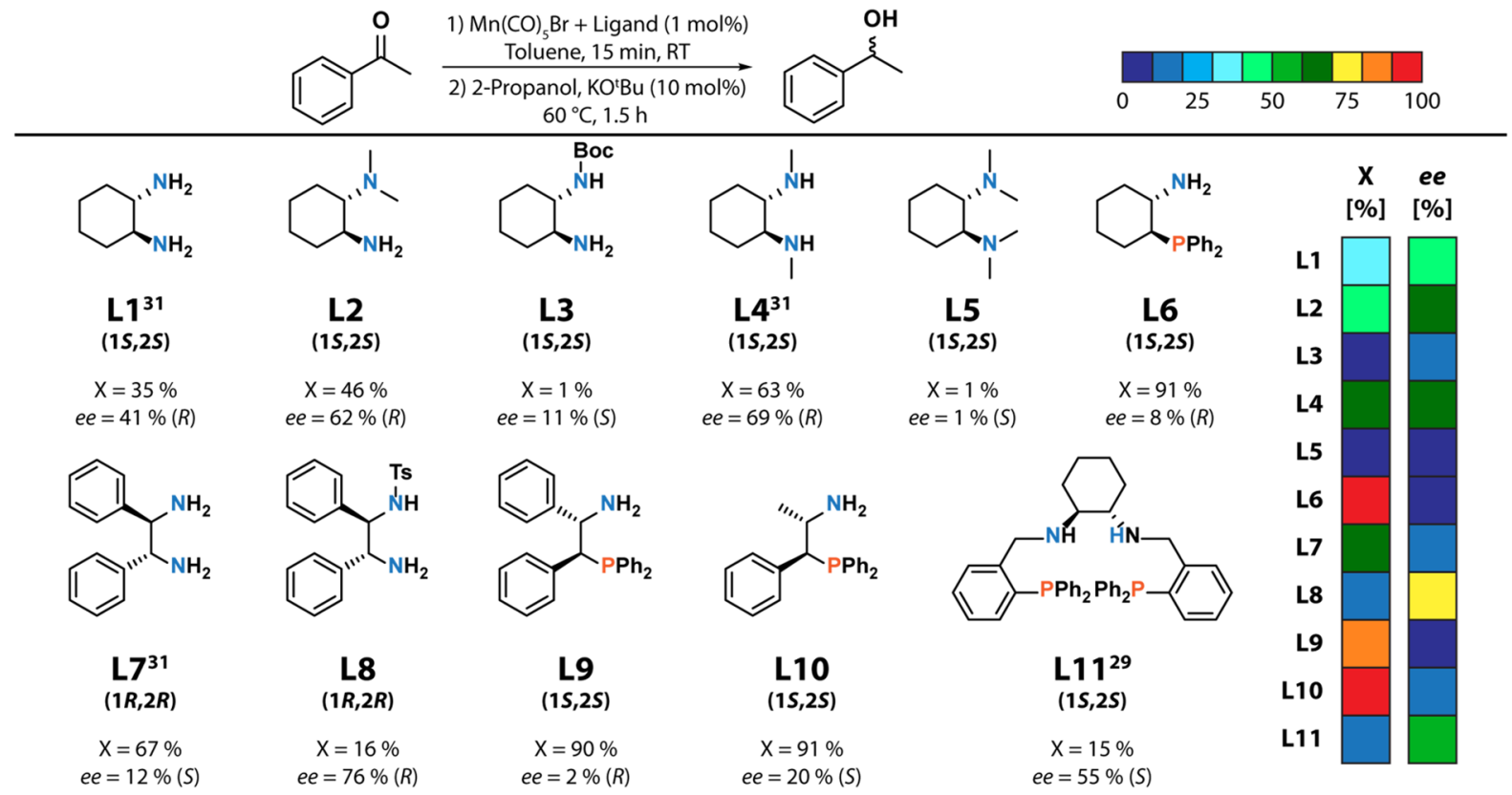

${ }^{a}$ Conditions: $0.5 \mathrm{mmol}$ of acetophenone, $10.0 \mathrm{~mol} \% \mathrm{KO}^{\mathrm{t}} \mathrm{Bu}, 1.0 \mathrm{~mol} \% \mathrm{Mn}(\mathrm{CO})_{5} \mathrm{Br}, 1.0 \mathrm{~mol} \%$ ligand, $2.5 \mathrm{~mL}$ of ${ }^{\mathrm{i}} \mathrm{PrOH}+0.5 \mathrm{~mL}$ of toluene, 60 ${ }^{\circ} \mathrm{C}, 1.5 \mathrm{~h}$. Yields determined by GC-FID using $n$-dodecane as an internal standard. A number of ligands have been evaluated before under slightly different conditions (see refs 29 and 31 ).

Scheme 3. Synthesis of Well-Defined Mn Precatalysts 1-Cis and 1-Trans ${ }^{a}$

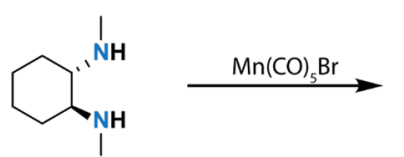

L4<smiles>CN(C(=O)[O-])[C@@H]1CCCC[C@H]1N(C)C(Cl)(Cl)Cl</smiles>

Major

Minor

1-Cis

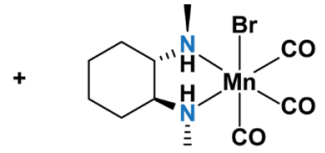

$n$-Hexane $\left(70^{\circ} \mathrm{C}\right)$

Minor

Major

1-Trans

${ }^{a}$ The mixture of cis and trans is denoted as $\mathbf{1}$.

Thus far, the open literature does not provide substantial mechanistic analysis of Mn-catalyzed ATH due to the lack of isolated or well-defined bidentate $\mathrm{Mn}$ complexes for the asymmetric transfer hydrogenation of ketones. Herein, we describe the identification, isolation, and characterization of a series of simple chiral $\mathrm{Mn}$-diamine catalysts. The combination of stoichiometric reactivity studies, DFT calculations, and analysis of reaction kinetics allowed the complex reactivity patterns of apparently simple $\mathrm{Mn}-\mathrm{N}, \mathrm{N}$ catalysts to be identified in the asymmetric transfer hydrogenation of ketones.

In-Situ Screening and Precatalyst Isolation. We began our studies by evaluating a series of readily available chiral diamines and aminophosphines as ligands for the Mn-catalyzed ATH of acetophenone (Scheme 2). The Mn complexes were prepared by stirring $\mathrm{Mn}(\mathrm{CO})_{5} \mathrm{Br}$ with 1 equiv of the chiral ligand in toluene at room temperature for $15 \mathrm{~min}$. The toluene solution with the $\mathrm{Mn} / \mathrm{L}$-combination was transferred into ${ }^{\mathrm{i}} \mathrm{PrOH}$ containing the substrate and $\mathrm{KO}^{\mathrm{t}} \mathrm{Bu}$ as a base. In these initial experiments, a catalyst loading of $1 \mathrm{~mol} \%$ with respect to acetophenone was used, while base was present at $10 \mathrm{~mol} \%$.

The highest catalytic activities were observed for bidentate aminophosphine ligands L6, L9, and L10, unfortunately with low ee's not exceeding $20 \%$. In contrast, a high enantiomeric excess of $76 \%$ was achieved with tosyl protected DPEN ligand L8 but at a much lower conversion compared to the unprotected DPEN ligand L7. Interestingly, dialkylated diaminocyclohexanes (L2 and L4) led to modest catalytic activity combined with good enantioselectivity, whereas nonalkylated analogue $\mathbf{L} \mathbf{1}$ was less active and selective, and tetra-alkylated ligand $\mathbf{L} \mathbf{5}$ showed no activity at all.

Having identified $N, N^{\prime}$-dimethyl 1,2-diaminocyclohexane L4 as the best ligand in our initial evaluation in terms of the tradeoff between activity and enantioselectivity, we sought to isolate the precatalyst formed upon complexation of $\mathbf{L 4}$ to $\mathrm{Mn}$ $(\mathrm{CO})_{5} \mathrm{Br}$ (Scheme 3). The corresponding complex 1 was readily formed upon refluxing in $n$-hexane for several hours and was obtained in $34 \%$ yield after recrystallization from DCM $/ n$ hexane/diethyl ether at $-20{ }^{\circ} \mathrm{C}$. The compound was fully characterized using ${ }^{1} \mathrm{H} /{ }^{13} \mathrm{C} \mathrm{NMR}$, FT-IR, elemental analysis, and single-crystal $\mathrm{X}$-ray analysis (see the Supporting Information).

Upon complexation, the methyl groups in L4 lose equivalency and appear in ${ }^{1} \mathrm{H}$ NMR of 1-Cis as two sharp doublets at $\delta=2.9 \mathrm{ppm}$ and $\delta=2.7 \mathrm{ppm}$ in $\mathrm{CD}_{2} \mathrm{Cl}_{2}$. We 

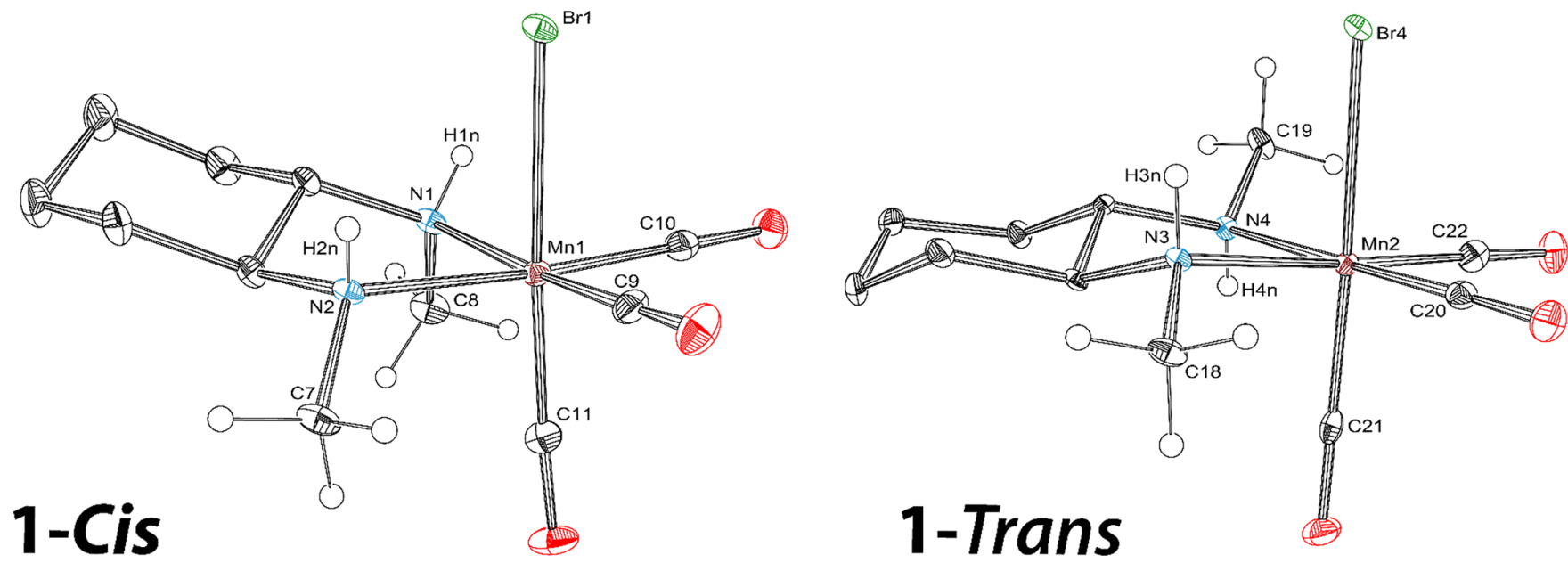

Figure 1. ORTEP diagrams of 1-Cis (left) and 1-Trans (right). Thermal ellipsoids are drawn at 30\% probability. Co-crystallized solvent and hydrogen atoms (except bound to nitrogen and $\mathrm{N}-\mathrm{Me}$ ) have been omitted for clarity.

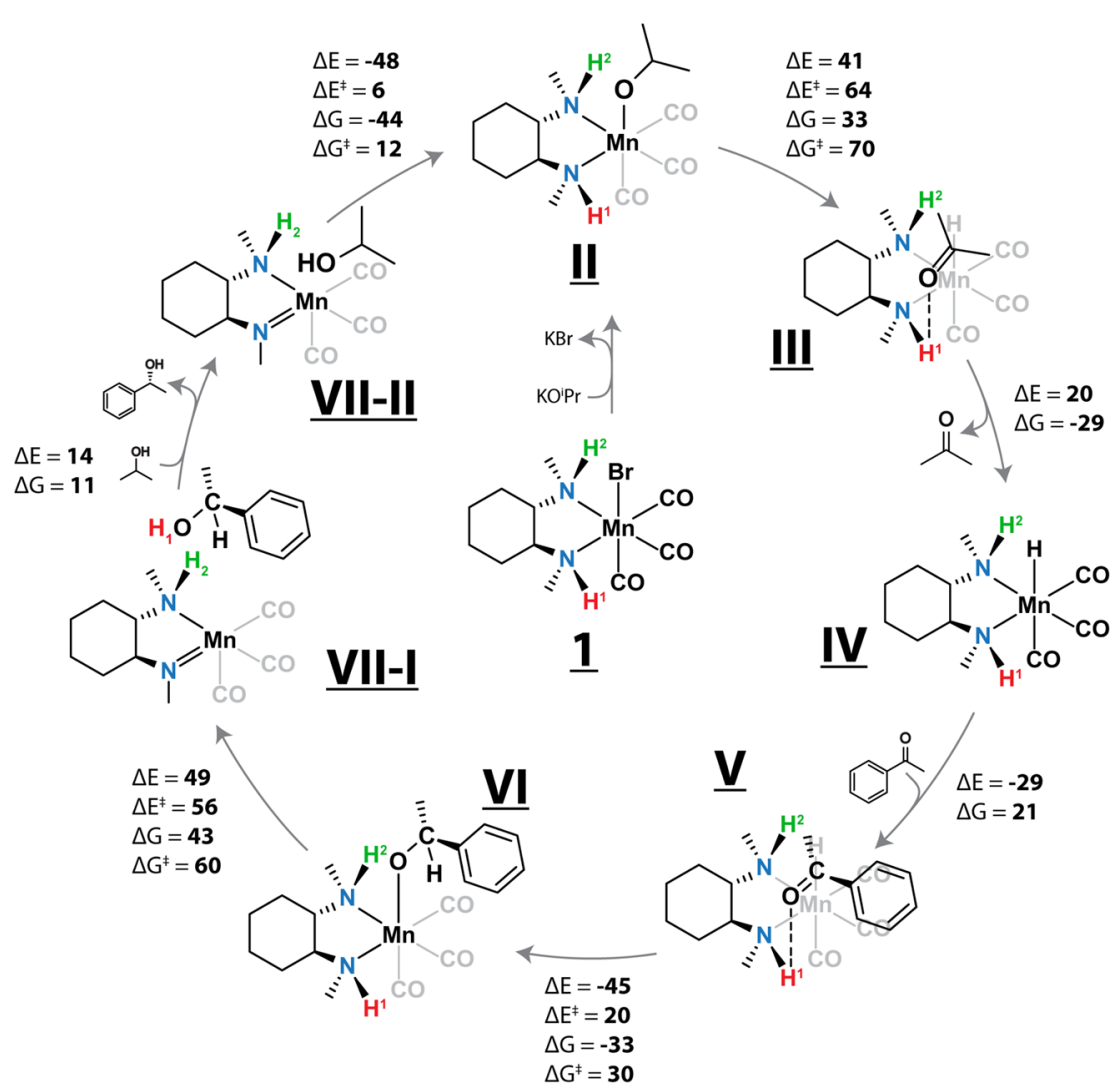

Figure 2. Proposed catalytic cycle for asymmetric transfer hydrogenation with 1-Cis. $\Delta G$ and $G^{\ddagger}$ represent reaction and activation Gibbs free energy changes in $\mathrm{kJ} \mathrm{mol}^{-1}$ at $333 \mathrm{~K}$, respectively. Cycle for formation of $(R)$-product shown.

hypothesize that the observed dissimilarity of the methyl groups originates from the locked chair conformation of the cyclohexane ring due to chelation to $\mathrm{Mn}$. The different steric environments of the axially and equatorially bound nitrogen atoms (i.e., varied proximity to ring-bound $\mathrm{C}-\mathrm{H}$ ) lead to the observation of the two distinct signals. The $\mathrm{NH}$ resonances of 1-Cis are present as two broad singlets at $\delta=3.3 \mathrm{ppm}$ and $\delta=$ $2.6 \mathrm{ppm}$, further indicating the chemical inequivalence of the amino groups (see the Supporting Information for full characterization).

Under the selected reaction conditions, we could observe the formation of a secondary product that has a distinct ${ }^{1} \mathrm{H}$
NMR spectrum from 1-Cis. This complex features a ${ }^{1} \mathrm{H}$ NMR spectrum in which resonances from the $\mathrm{NH}$ and $\mathrm{N}-\mathrm{Me}$ groups overlap and produce a band of signals between $\delta=3.0-2.8$ $\mathrm{ppm}$. This compound could be separated from 1-Cis by slow vapor diffusion crystallization from the original mother liquor by further addition of $n$-hexane (see the Supporting Information, 1-Trans, procedure A).

Single-crystal X-ray diffraction data of both products revealed their identities as cis and trans isomers. The solidstate structure of 1-Cis features the methyl groups bound in cis fashion, both oriented in opposite direction to the bromide ligand bound in the axial position of octahedral complex 1-Cis 
Scheme 4. DFT Calculations into the Origin of Enanantioselectivity of Catalysis with Mn-Hydrides $\mathrm{V}-\mathrm{H}^{1}$ and $\mathrm{V}-\mathrm{H}^{2} a$

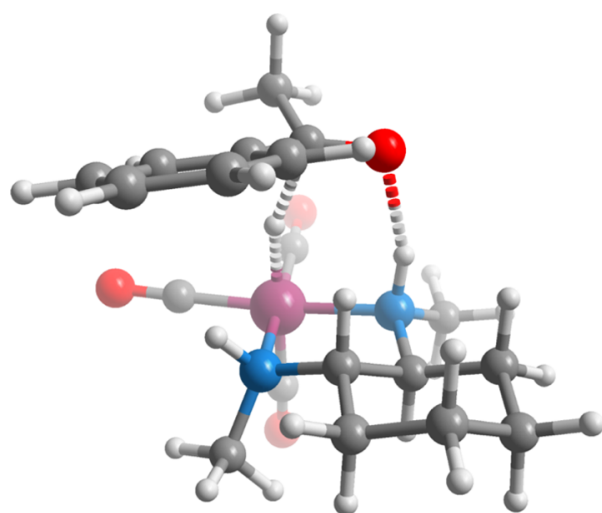

V-H ${ }^{1} / \mathrm{Si} /(\boldsymbol{R})$

Favorable

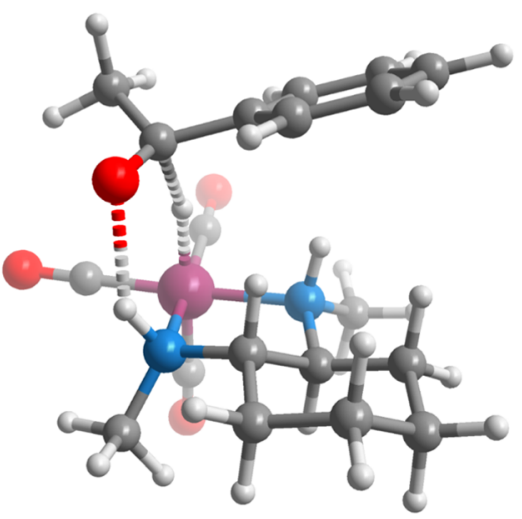

$\mathbf{V}-\mathrm{H}^{2} / \operatorname{Re} /(\mathrm{S})$

Favorable

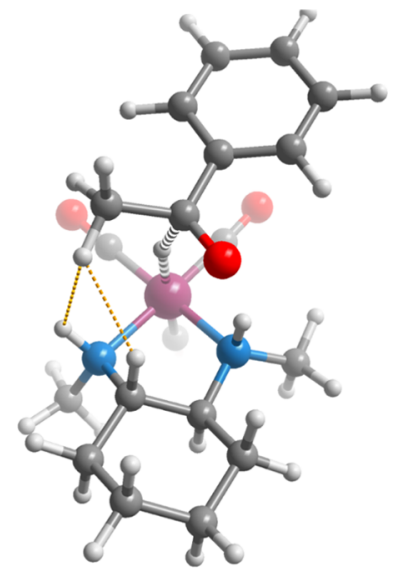

$\mathrm{V}-\mathrm{H}^{1} / \operatorname{Re} /(\mathrm{S})$

Unfavorable

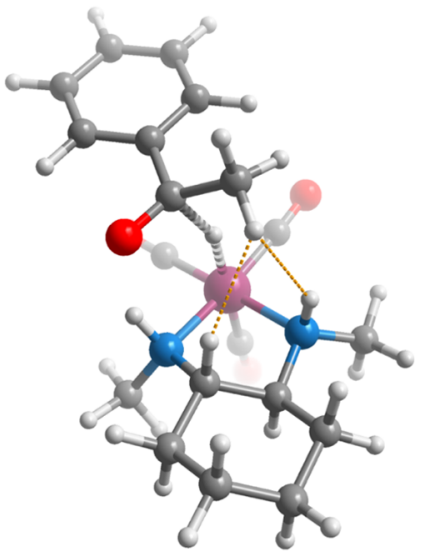

V-H $\mathrm{H}^{2} / \mathrm{Si} /(\boldsymbol{R})$

Unfavorable

\begin{tabular}{ccccccc}
\hline \multirow{2}{*}{ Product } & \multicolumn{4}{c}{ 1-Cis } & \multicolumn{2}{c}{ 1-Trans } \\
\cline { 2 - 7 } & \multicolumn{2}{c}{ Reaction Site $\left(\mathrm{H}^{1}\right)$} & \multicolumn{2}{c}{ Reaction Site $\left(\mathrm{H}^{2}\right)$} & \multicolumn{2}{c}{ Reaction Site $\left(\mathrm{H}^{1}\right)$} \\
& $\Delta \mathrm{E}^{\ddagger}$ & $\Delta \mathrm{G}^{\ddagger}$ & $\Delta \mathrm{E}^{\ddagger}$ & $\Delta \mathrm{G}^{\ddagger}$ & $\Delta \mathrm{E}^{\ddagger}$ & $\Delta \mathrm{G}^{\ddagger}$ \\
\hline (R)-1-Phenylethanol & 20 & $\mathbf{3 0}$ & 31 & 44 & 20 & $\mathbf{3 3}$ \\
(S)-1-Phenylethanol & 26 & 40 & 22 & 39 & 25 & $\mathbf{4 0}$ \\
\hline
\end{tabular}

${ }^{a}$ Dotted yellow lines highlight steric interactions of unfavorable high-energy TS.

(Figure 1). The second product was identified as 1-Trans, a minor isomer $(<20 \%)$ of $\mathbf{1}$ in which the $\mathrm{NH}$ protons are oriented trans (Figure 1). The ratio of 1-Cis/1-Trans was found to be strongly dependent on the complexation conditions; a nearly inverse ratio of 1-Cis/1-Trans was obtained when the reaction was performed in dichloromethane at $25{ }^{\circ} \mathrm{C}$ (Scheme 3 ).

Isomers 1-Cis and 1-Trans did not interconvert upon prolonged heating at $70{ }^{\circ} \mathrm{C}$ in THF- $d_{8}$ or $\mathrm{C}_{6} \mathrm{D}_{6}$, indicating that their formation and relative abundance is a kinetic ratio governed by synthetic conditions rather than chemical exchange phenomena. Additionally, no ligand substitution occurred when 1-Cis or 1-Trans was refluxed in benzene in the presence of 2 equiv of triphenylphosphine, further confirming their thermal and chemical stability. The presence of a 2 -fold L4 excess during complexation did not result in the formation of cationic $\left[\mathrm{Mn}(\mathrm{L})_{2}(\mathrm{CO})_{2}\right]^{+}$species, which are frequently observed when stronger phosphine-donor ligands are utilized. $^{27,28,34}$

With the isolated complexes 1-Cis and 1-Trans in hand, we tested whether they would have different catalytic performances. Both complexes, however, produced a virtually identical yield of $(R)$-1-phenylethanol of $\sim 40 \%$ in $1 \mathrm{~h}$ at $60{ }^{\circ} \mathrm{C}$ with $74 \%$ ee, which is a slight improvement in performance over the situation when the catalyst was generated in situ (Table S2). Preactivation of precatalysts 1-Cis and 1-Trans with $\mathrm{NaHBEt}_{3}{ }^{30,35}$ allowed the catalytic reaction to be operated base free. Catalytic performance was not improved and was identical for both complexes, again indicating that the catalytically active species formed from precatalysts 1-Cis and 1-Trans are identical.

Mechanistic Investigations and Origin of Stereoselectivity. We next employed density functional theory (DFT) to rationalize the observed trends in catalysis with complexes 1-Cis and 1-Trans. The reaction mechanism was 
Scheme 5. Stoichiometric Reactivity Studies with Complexes 1-Cis and 1-Trans

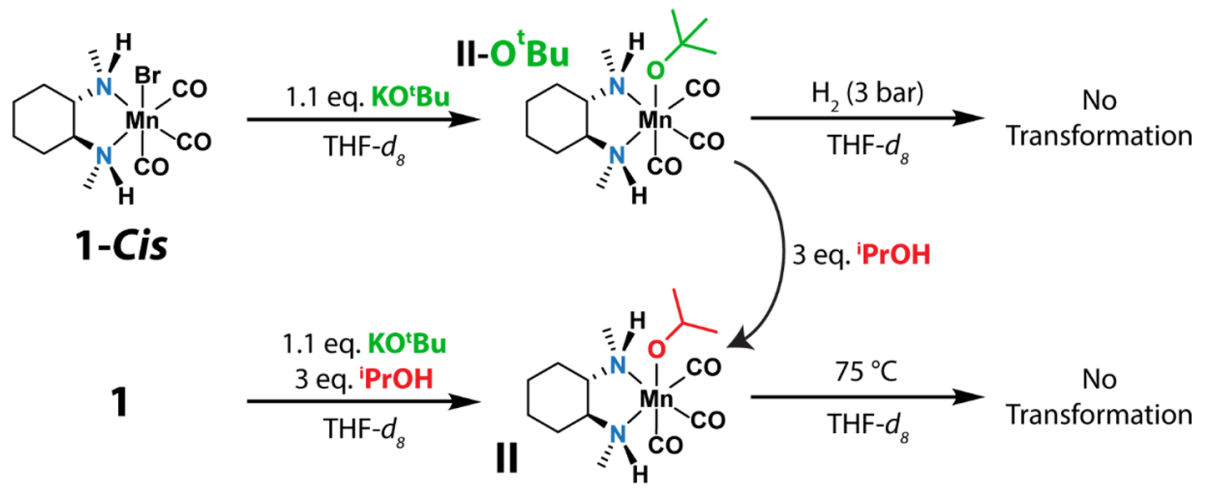

Scheme 6. Isolated Chiral Manganese-Diamine Complexes<smiles>C[C@@H]1N(C)[C@H]2CCCC[C@H]2N1[R14](Cl)(Br)C=O</smiles>

1-Cis<smiles>CN1[C@H]2CCCC[C@H]2N(C)[Y10](Br)(C(=O)[O-])[C@H]1C=O</smiles>

1-Trans

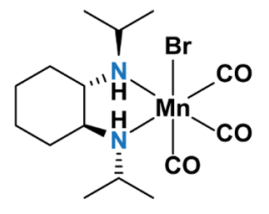

1-Trans-'Pr<smiles>CN1[C@@H]2CCCC[C@@H]2[N@@+](C)(C=O)[C@@]1(C=O)C(=O)O</smiles>

2 investigated at the PBE0-D3(BJ)-SMD $\left({ }^{\mathrm{i}} \mathrm{PrOH}\right) / \mathrm{Def} 2 \mathrm{QZVPP}$ level of theory using the Gaussian 09 D.01 program. ${ }^{36}$ The proposed catalytic mechanism as well as reaction and standard activation Gibbs free energies for elementary steps are summarized in Figure 2.

The catalytic cycle starts by activation of precatalyst 1-Cis with $\mathrm{KO}^{\mathrm{t}} \mathrm{Bu}$ and ${ }^{\mathrm{i}} \mathrm{PrOH}$ (or $\mathrm{KO}^{\mathrm{i}} \mathrm{Pr}$, created in situ) to form $\mathrm{Mn}$-isopropoxide complex II, which is a resting state in the catalytic cycle. $\beta$-Hydride elimination of the anionic isopropoxide ligand with concomitant formation of $\mathrm{Mn}$-hydride complex III proceeds with the highest activation Gibbs free energy in the catalytic cycle of $70 \mathrm{~kJ} \mathrm{~mol}^{-1}$. Acetone is removed from III to produce catalytically active $\mathrm{Mn}$-hydride IV. The ketone substrate subsequently coordinates to IV via $\mathrm{NH}$-assisted hydrogen bonding, forming $\mathrm{Mn}$-adduct $\mathbf{V}$, and reacts endergonically $\left(\Delta G^{\ddagger}{ }_{(R)}=30 \mathrm{~kJ} \mathrm{~mol}^{-1}, \Delta G^{\ddagger}{ }_{(S)}=39 \mathrm{~kJ}\right.$ $\mathrm{mol}^{-1}$ ) through enantiodetermining hydride transfer, leading to the formation of $\mathrm{Mn}$-alkoxide resting state VI. Liberation of the 1-phenylethanol product is an activated process with a high barrier of $60 \mathrm{~kJ} \mathrm{~mol}^{-1}$ and results in the formation of reactive Mn-amido intermediate VII-I. Deprotonated complex VIIII readily reacts with free ${ }^{\mathrm{i}} \mathrm{PrOH}$ in an exergonic reaction with a low barrier of only $12 \mathrm{~kJ} \mathrm{~mol}^{-1}$ to regenerate $\mathrm{MnO}$ Pr species II and complete the catalytic cycle.

Cis-complex 1-Cis possesses two accessible and reactive N$H$ moieties $\left(\mathrm{H}^{1}\right.$ and $\mathrm{H}^{2}$ in Figure 2), whereas trans-ligated systems only bear one $\left(\mathrm{H}^{1}\right)$. The steric environment of both $\mathrm{N}-\mathrm{H}^{\prime}$ 's, however, is different because of the close proximity of up-and-down oriented carbon/hydrogen atoms in the cyclohexyl ring (Scheme 4). This difference potentially impacts stereoselectivity, as it may lead to preferential precoordination of the Re or Si face of acetophenone to 1-Cis and 1-Trans. We therefore studied the enantiodeterminative step in more detail using DFT and calculated the energies for coordination of the $R e$ and $S i$ faces of acetophenone to all reactive protons, i.e., four combinations for 1-Cis and two for 1-Trans (Scheme 4). These studies revealed preferential formation of $(R)-1$ phenylethanol for both conformers which originates from coordination of the $\mathrm{Si}$ face to proton $\mathrm{H}^{1}$. Enantioselective induction is predominantly achieved through steric repulsion between the substrate $\mathrm{CH}_{3}$ and nearby ligand-bound $\mathrm{CH}$ and $\mathrm{NH}$ (transition states for 1-Cis shown in Scheme 4).

The differences in activation barriers for the transfer of proton $\mathrm{H}^{1}$ are 9 and $7 \mathrm{~kJ} \mathrm{~mol}^{-1}$ between $\mathrm{H}^{1}$ and $\mathrm{H}^{2}$ for cis and trans $\mathbf{V}$-hydrides, respectively (details in Scheme 4 and the Supporting Information). Thus, reaction at $\mathrm{H}^{2}$ is a more activated process and results in $(S)$-alcohols. Calculated results correctly predict the preferential formation of the major $(R)$ enantiomer found experimentally and, contrary to our original hypothesis, predict virtually identical enantioselective performance of 1-Cis and 1-Trans.

A stoichiometric reactivity study was performed using ${ }^{1} \mathrm{H}$ NMR spectroscopy to experimentally substantiate results obtained with DFT. Reaction of 1-Cis and $\mathrm{KO}^{\mathrm{t}} \mathrm{Bu}$ in THF- $d_{8}$ (i.e., in the absence of ${ }^{\mathrm{i}} \mathrm{PrOH}$ ) led to the formation of a new octahedral $\mathbf{M n}$-alkoxide complex II- $\mathbf{O}^{\mathbf{t}} \mathbf{B u}$ (Scheme 5, top), evidenced by the significant change of the ${ }^{1} \mathrm{H}$ NMR spectrum (Figure S18). Addition of ${ }^{\mathrm{i}} \mathrm{PrOH}$ to a solution of $\mathbf{I I}-\mathbf{O}^{\mathbf{t}} \mathbf{B u}$ in THF- $d_{8}$ resulted in a rapid color change of the reaction mixture from red to yellow, associated with the formation of the $\mathrm{Mn}$-isopropoxide complex II. The identity of neutral complex II is suggested on the basis of ${ }^{1} \mathrm{H}$ NMR, indicated by the appearance of a new resonance at $\delta=4.07 \mathrm{ppm}$ that is assigned to the Mn-bound isopropoxide moiety. Interestingly, the ${ }^{\mathrm{i}} \mathrm{PrO}$ anion in $\mathrm{II}$ is dynamic and rapidly exchanges with free ${ }^{i} \mathrm{PrOH}$ in solution, as evidenced by $2 \mathrm{D}-\mathrm{NOE}$ measurements (Figure S34). The same cis-Mn-alkoxides II- $\mathbf{O}^{\mathbf{t}} \mathbf{B u}$ and II were formed upon treatment of 1-Cis or 1-Trans with $\mathrm{KO}^{t} \mathrm{Bu}$ in the absence of ${ }^{\mathrm{i}} \mathrm{PrOH}\left(\mathbf{I I}-\mathbf{O}^{\mathbf{t}} \mathbf{B u}\right)$ or with ${ }^{\mathrm{i}} \mathrm{PrOH}$ (II). This observation implies that the treatment of 1-Trans with $\mathrm{KO}^{t} \mathrm{Bu}$ converts it into a complex where both protons and methyls are in a cis-configuration. Consequently, both isomers 1-Cis and 1Trans show an identical catalytic reactivity and selectivity in the ATH reaction.

Interestingly, even in the presence of minor quantities ${ }^{i} \mathrm{PrOH}$ (ca. $2-3$ equiv), $\mathrm{Mn}$-isopropoxide complex II appears 
a

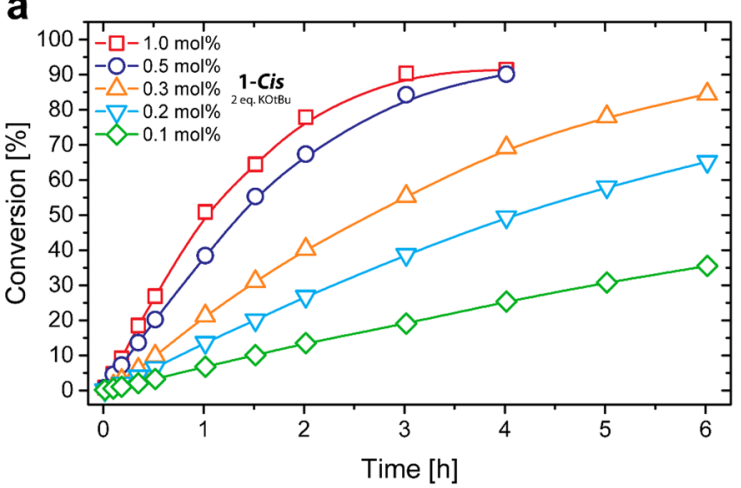

C

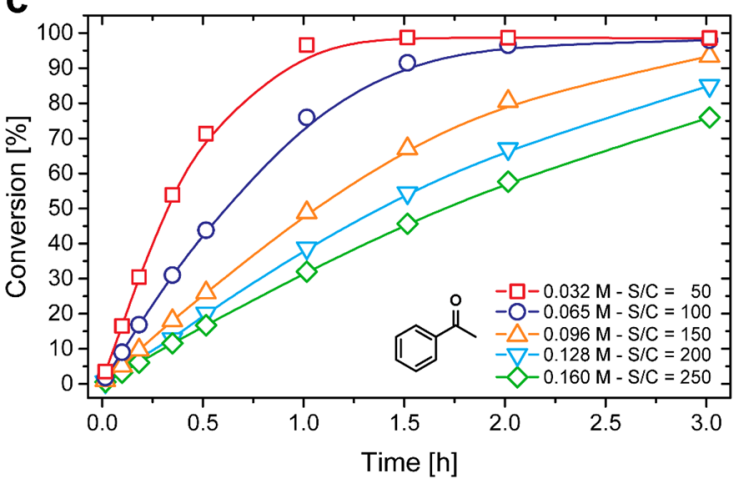

e

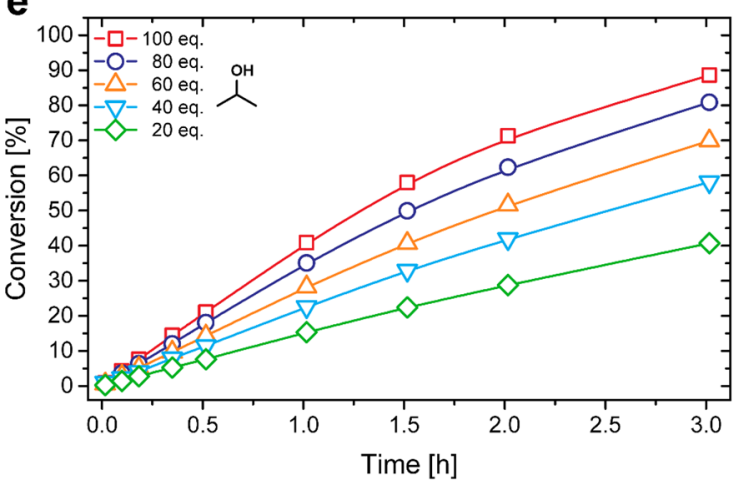

b

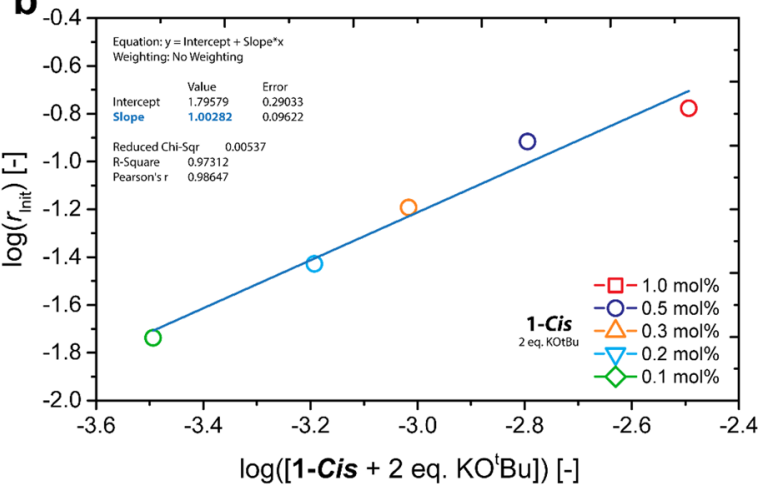

d

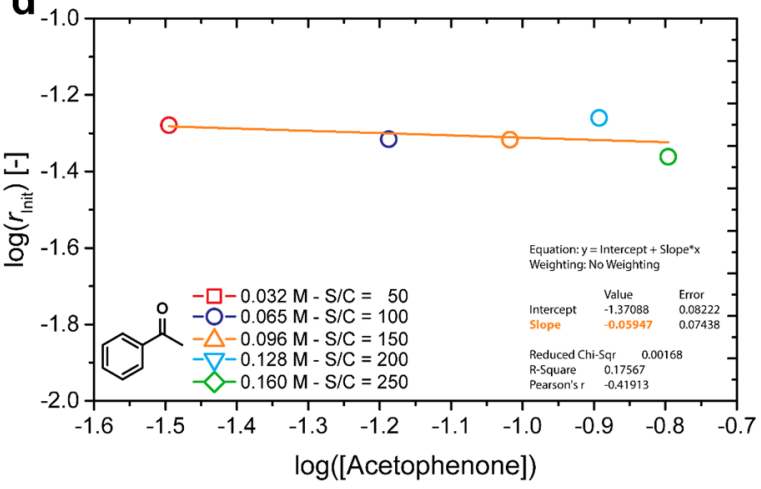

f

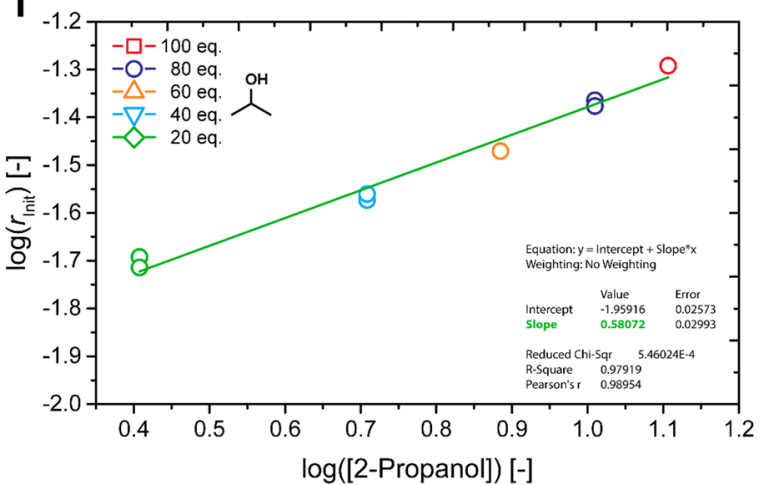

Figure 3. Kinetic reaction analysis of 1-Cis catalyzed ATH of acetophenone. (a, b) Reaction order determination for 1-Cis +2 equiv of KO Bu. (c, d) Reaction order determination for acetophenone. (e, f) Reaction order determination for 2-propanol. Conditions unless otherwise noted: 0.5 mmol of acetophenone $(0.128 \mathrm{M}), 1.0 \mathrm{~mol} \% \mathrm{KO}^{\mathrm{t}} \mathrm{Bu}, 0.5 \mathrm{~mol} \%$ 1-Cis, $3.82 \mathrm{~mL}$ of ${ }^{\mathrm{i}} \mathrm{PrOH}$ (diluted with toluene for parts e and f), $60{ }^{\circ} \mathrm{C}$. Yields determined by GC-FID using $n$-dodecane as an internal standard.

to be remarkably stable at temperatures tested up to $75^{\circ} \mathrm{C}$ and does not produce any dehydrogenation products (e.g., acetone). This observation is in stark contrast to the behavior of aminopincer Mn-PNP or Mn-NHC complexes, ${ }^{25,26}$ which are known to promote secondary alcohol dehydrogenation and typically form readily observable manganese-hydride complexes. ${ }^{37}$ Complex II, however, reduces acetophenone to the corresponding alcohol, despite the notable absence of detectable hydride resonances in ${ }^{1} \mathrm{H}$ NMR (Figure S25). Furthermore, $\mathbf{I I}-\mathbf{O}^{\mathbf{t}} \mathbf{B u}$ is resilient toward heterolytic hydrogen activation under basic conditions and did not form detectible amounts of $\mathrm{Mn}$-hydride species upon pressurization with 3 bar of hydrogen gas.

We hypothesized that the introduction of more sterically demanding $\mathrm{N}$-alkyl groups on the chiral ligand could improve the stereoselectivity. To test this hypothesis, complex 1Trans $-{ }^{\mathrm{i}}$ Pr was prepared (Scheme 6). ATH of acetophenone with 1-Trans $-{ }^{\mathrm{i}} \operatorname{Pr}$ led to the formation of $(R)$-1-phenylethanol with an identical ee of $71 \%$ as with 1-Cis and 1-Trans, while catalytic activity was dramatically reduced to only one turnover (Table S2). Fully methylated complex 2 did not show any catalytic activity, therewith stressing the importance of accessible $\mathrm{NH}$ protons and confirming the proposed bifunctional mechanism involving protonation/deprotonation of the amino group of 1-Cis and 1-Trans.

Compounds 1-Cis and 1-Trans are moderately enantioselective ketone transfer hydrogenation catalysts, which may be beneficial for future benchmarking of computational models and methods. We carried out a detailed kinetic analysis of the ATH using acetophenone as a model substrate with 1-Cis. At $60{ }^{\circ} \mathrm{C}$, complex 1 -Cis $(0.5 \mathrm{~mol} \%)$ reacts with an initial turnover frequency of $79 \mathrm{~h}^{-1}$ and $(R)$-1-phenylethanol is produced quantitatively in $4 \mathrm{~h}$ with $73 \%$ ee. The initial reaction rates increase with increased catalyst loading (0.1-1.0 mol \% 
Scheme 7. In-Situ Preparation and Detection of Mn-Alkoxide II-OPhEt
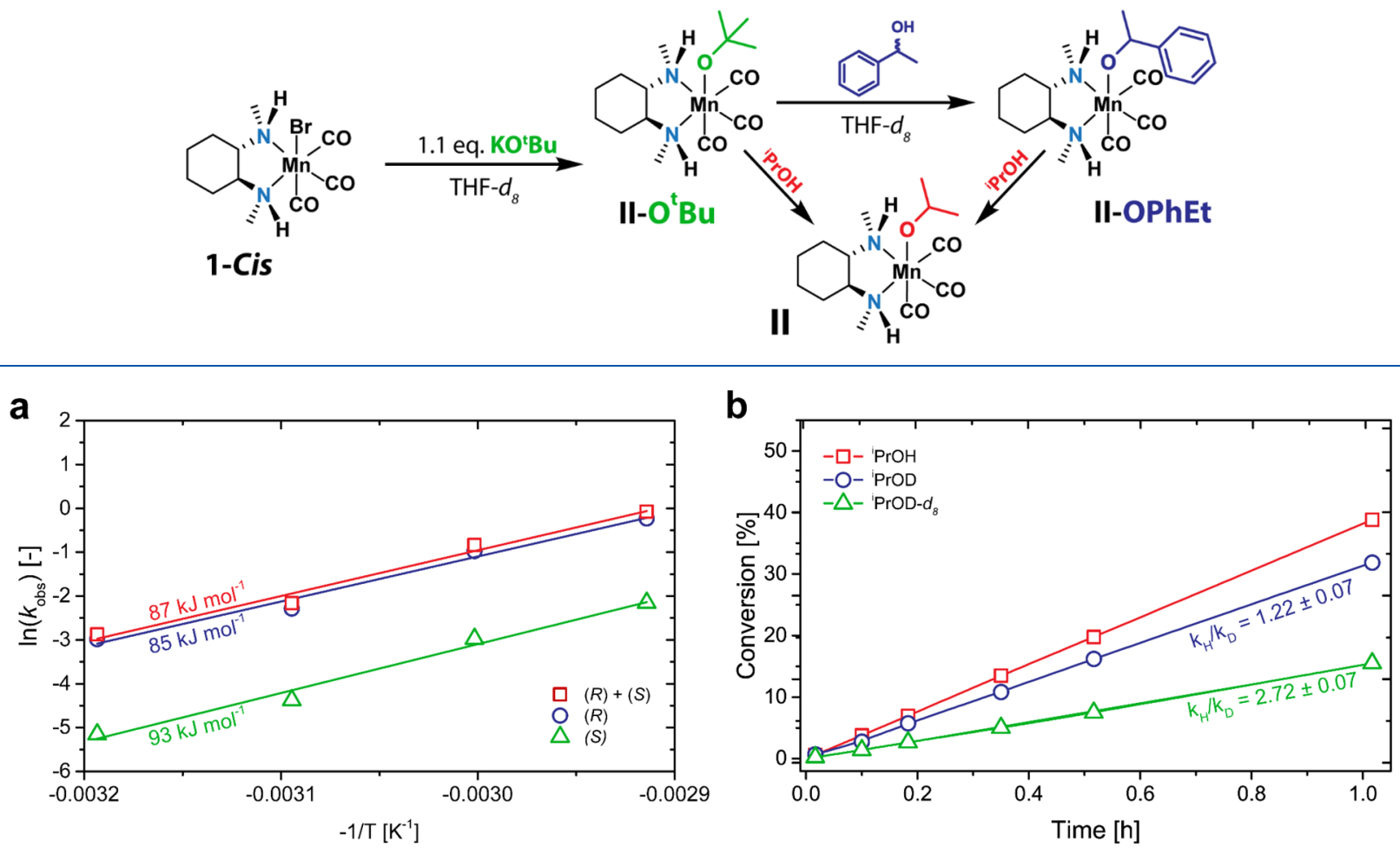

Figure 4. (a) Arrhenius plot for acetophenone ATH with 1-Cis (left). (b) Kinetic isotope effect studies for ATH with 1-Cis (right). Conditions: 0.5 mmol of acetophenone $(0.128 \mathrm{M}), 1.0 \mathrm{~mol} \% \mathrm{KO}^{\mathrm{t}} \mathrm{Bu}, 0.5 \mathrm{~mol} \% 1-\mathrm{Cis}, 3.82 \mathrm{~mL}$ of ${ }^{\mathrm{i}} \mathrm{PrOH}$ or ${ }^{\mathrm{i}} \mathrm{PrOD}, 40-70{ }^{\circ} \mathrm{C}$. Yields determined by GC-FID using $n$-dodecane as an internal standard.

1-Cis) and are in agreement with a catalyst reaction order of 1.0 (Figure 3a,b and the Supporting Information). The influence of base concentration on precatalyst activation and the catalytic reaction rate was evaluated at various base loadings (see the Supporting Information). No effect is observed when 2-20 equiv of base relative to 1-Cis was used, while lower base concentration resulted in reduced catalytic performance. Additionally, the catalyst reaction order in the presence of a large excess $(5 \mathrm{~mol} \%)$ of $\mathrm{KO}^{\mathrm{t}} \mathrm{Bu}$ similarly was equal to 1.0 (see the Supporting Information). Thus, all observations suggest that base solely acts as the precatalyst activator and does not play a significant role in the catalytic cycle for ATH.

The interpretation of kinetic data for acetophenone and ${ }^{\mathrm{i}} \mathrm{PrOH}$ is less straightforward and revealed orders of 0 and 0.6 , respectively (Figure 3c-f). Previously, Heeres and co-workers have derived a kinetic rate equation for the Ru-catalyzed ATH of ketones, taking into account effects caused by the reverse reaction (terms in the nominator), and effects due to catalyst inhibition by acetophenone (A), ${ }^{\mathrm{i}} \mathrm{PrOH}$ (B), 1-phenylethanol (C), and acetone (D) (terms in the denominator), with parameters $k, m, n$, and $p$, as the reaction orders for inhibition caused by the respective reaction component (eq 1$).^{38}$

$$
\begin{aligned}
-\frac{\mathrm{d} C_{A}}{\mathrm{~d} t} & =-r_{A}=\frac{k_{1}^{+} C_{A} C_{B}-k_{1}^{-} C_{C} C_{D}}{1+k_{2} C_{A}^{k}+k_{3} C_{B}^{m}+k_{4} C_{C}^{n}+k_{5} C_{D}^{p}} \\
-\frac{\mathrm{d} C_{A}}{\mathrm{~d} t} & =-r_{A}=\frac{k_{1}^{+} C_{A} C_{B}}{1+k_{2} C_{A}^{k}+k_{3} C_{B}^{m}}
\end{aligned}
$$

At the start of the reaction, one can assume a negligible influence from the reverse reaction and its product (i.e., $\mathrm{C}$ and
D), and the kinetic rate equation simplifies to eq 2. Both DFT and stoichiometric reactivity studies suggest a rapid reaction of the activated complex with ${ }^{\mathrm{i}} \mathrm{PrOH}$ (B) to $\mathrm{MnO}^{\mathrm{i}} \mathrm{Pr}$ complex II. The $\beta$-H elimination step to convert II to $\mathrm{Mn}$-hydride III and acetone is the rate-determining step (RDS) in the catalytic cycle. Subsequent elementary reactions lead to transfer of the hydride to acetophenone through a sequence of low-barrier transformations (Figure 2). This process is similar to conventional saturation kinetics ${ }^{39}$ and is consistent with a zeroth order reaction rate in acetophenone, since the substrate is not involved in the RDS.

The predicted facile formation of $\mathrm{Mn}$-alkoxide II also provides a rationalization for the positive fractional reaction order of the hydrogen donor and solvent, ${ }^{\mathrm{i}} \mathrm{PrOH}$. If inhibition by ${ }^{\mathrm{i}} \mathrm{PrOH}$ is much faster than substrate inhibition (i.e., $k_{3} C_{B}{ }^{m}$ $\gg 1+k_{2} C_{A}{ }^{k}$ ) and $\mathrm{C}_{\mathrm{A}}$ effectively is constant, eq 2 can be further reduced to eq 3 . The extent of inhibition by ${ }^{\mathrm{i}} \mathrm{PrOH}$, as expressed in parameter $m$, directly impacts the observed reaction order in ${ }^{\mathrm{i}} \mathrm{PrOH}$, leading to the positive fractional reaction order value of 0.6 for ATH with 1-Cis.

$$
\begin{aligned}
-\frac{\mathrm{d} C_{A}}{\mathrm{~d} t} & =-r_{A}=\frac{k_{1}^{+} C_{A} C_{B}}{k_{3} C_{B}^{m}}=K_{\mathrm{obs}} C_{B}^{1-m} \text { with } \\
K_{\mathrm{obs}} & =\frac{k_{1}^{+} C_{A}}{k_{3}}
\end{aligned}
$$

The relative stability of $\mathrm{Mn}$-alkoxide complexes in hydrogenations has been observed before by our group for closely related $\mathrm{Mn}-\mathrm{P}, \mathrm{N}$ complexes. ${ }^{34,40}$ This led us to investigate the extent of product inhibition in ATH with 1-Cis by means of additional stoichiometric reactivity studies. The $\mathrm{Mn}-1$ - 

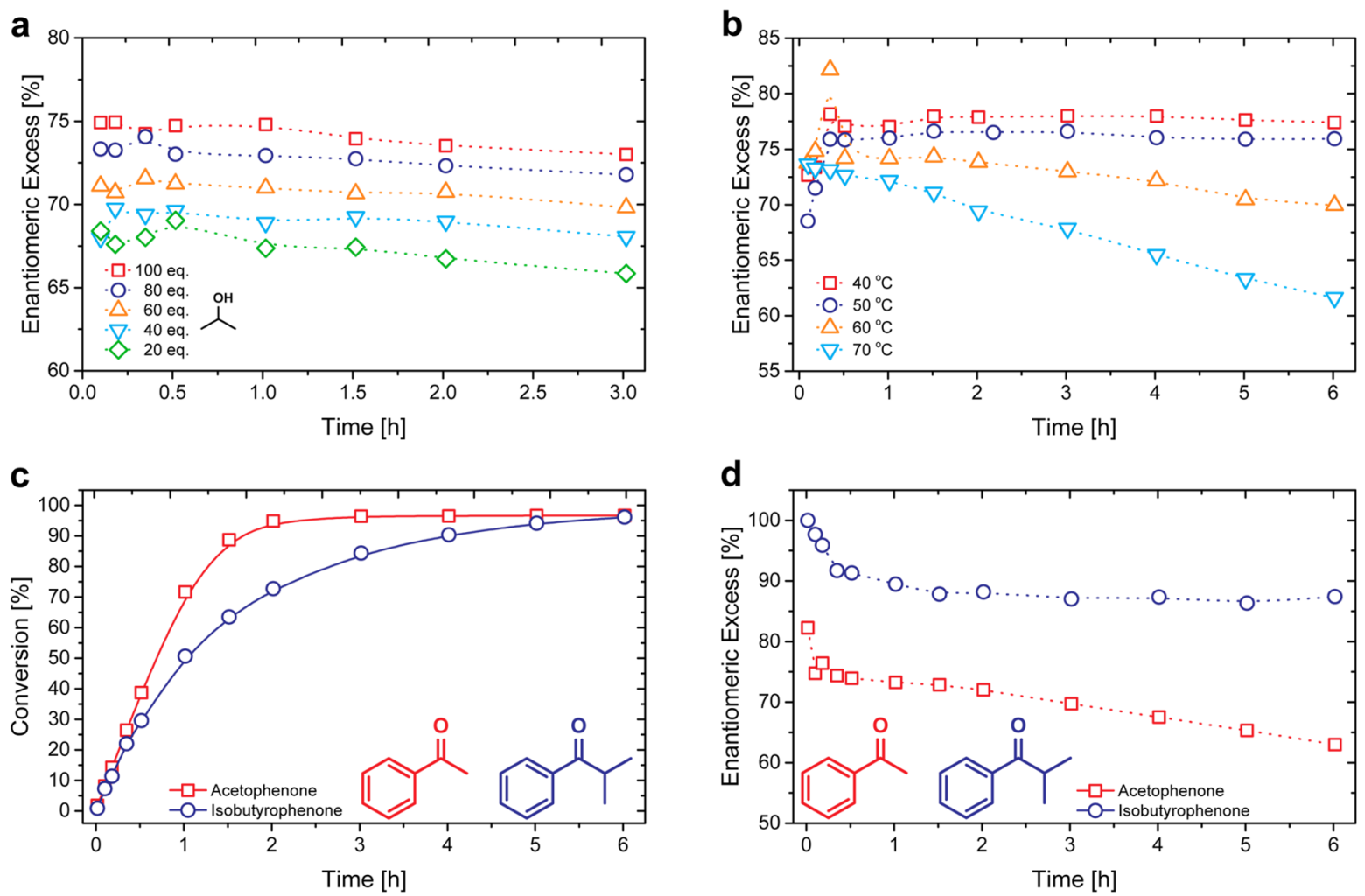

Figure 5. (a) Erosion of ee as a function of ${ }^{\mathrm{i}} \mathrm{PrOH}$ concentration. (b) Erosion of ee as a function of reaction temperature. (c) Reaction rate of acetophenone and isobutyrophenone ATH with 1-Cis. (d) Erosion of ee for acetophenone and isobutyrophenone ATH. Conditions unless otherwise noted: $0.5 \mathrm{mmol}$ of acetophenone $(0.128 \mathrm{M}), 1.0 \mathrm{~mol} \% \mathrm{KO}^{\mathrm{t}} \mathrm{Bu}, 0.5 \mathrm{~mol} \%$ 1-Cis $\left(2.0 \mathrm{~mol} \% \mathrm{KO}^{\mathrm{t}} \mathrm{Bu}\right.$ and $1.0 \mathrm{~mol} \%$ 1-Cis for parts $\mathrm{c}$ and d), $3.82 \mathrm{~mL}$ of ${ }^{\mathrm{i}} \mathrm{PrOH}$ (diluted with toluene for parts a and b), $40-70{ }^{\circ} \mathrm{C}$. Yields determined by GC-FID using $n$-dodecane as an internal standard.

phenylethoxide complex II-OPhEt was detected with ${ }^{1} \mathrm{H}$ NMR after reaction of $\mathbf{1 - C i s}$ or $\mathbf{I I}-\mathbf{O}^{\mathbf{t}} \mathbf{B u}$ with 1-phenylethanol and base (Scheme 7). Addition of $\sim 3$ equiv of ${ }^{\mathrm{i}} \mathrm{PrOH}$ led to the formation of a mixture of $\mathrm{Mn}$-alkoxide complexes II and II-OPhEt, suggesting both may be present and that product inhibition cannot be ruled out in catalysis with $\mathbf{1 - C i s}$.

In summary, catalyst inhibition by ${ }^{\mathrm{i}} \mathrm{PrOH}$ is a significant process for the 1-Cis-catalyzed ATH of ketones and results in observed zeroth order kinetics for the substrate and a positive fractional reaction order for the hydrogen donor.

Activation Energies and KIE Measurements. We concluded our mechanistic studies with the determination of apparent activation energies and kinetic isotope effect (KIE) measurements to get a better experimental insight into the RDS. Acetophenone ATH with 1-Cis proceeds with an apparent, nonasymmetric activation energy of $87 \mathrm{~kJ} \mathrm{~mol}^{-1}$ (Figure 4a). Detailed analysis of reaction rates allowed determination of the apparent $E_{\mathrm{A}}$ for the formation of individual $(R)$ and $(S)$ enantiomers, which is particularly useful for benchmarking computational models. The reaction to $(R)$-1-phenylethanol exhibits a barrier of $85 \mathrm{~kJ} \mathrm{~mol}^{-1}$, while the pathway to $(S)$-1-phenylethanol proceeds with a marginally higher barrier of $93 \mathrm{~kJ} \mathrm{~mol}^{-1}$. This observed $\Delta \Delta E_{\mathrm{A}}$ App of $8 \mathrm{~kJ}$ $\mathrm{mol}^{-1}$ for formation of both enantiomers corresponds well with the computed value of $\Delta \Delta G^{\ddagger}$ for ATH of acetophenone with 1-Cis (Scheme 4), with the overall observed and predicted barriers for the RDS showing some difference $(\Delta \Delta E$ of $15 \mathrm{~kJ}$ $\mathrm{mol}^{-1} ; 70 \mathrm{~kJ} \mathrm{~mol}^{-1}$ from DFT versus experimental $85 \mathrm{~kJ}$ $\mathrm{mol}^{-1}$ ). At this moment, however, it remains unclear what is the cause of this observed divergence between theory and experiments.
Studies in ${ }^{\mathrm{i}} \mathrm{PrOD}-d_{8}$ reveal a strong primary kinetic isotope effect (KIE) of $2.72 \pm 0.07$, consistent with hydride transfer from ${ }^{\mathrm{i}} \mathrm{PrOH}$ being involved in the RDS of the catalytic cycle. This finding correlates well with the proposed mechanism (Figure 2), where $\beta$-hydride elimination from the coordinated isopropoxide ligand to form $\mathrm{Mn}$-hydride III was identified as the most energetically demanding transformation. When ${ }^{i}$ PrOD was used, we observed a secondary KIE of $1.22 \pm$ 0.07 (Figure $4 \mathrm{~b}$ ). Proton transfer is clearly of less importance than hydride transfer, yet this process too has a clear impact on the rate-determining processes in the catalytic reaction mechanism.

ee Erosion and Preservation. The reversible nature of the transfer hydrogenation reaction of ketones with secondary alcohols as hydrogen donors is known to induce an erosion of product enantiomeric excess. ${ }^{41}$ A strategy to prevent such ee erosion is to use an azeotropic mixture of formic acid and triethylamine as the hydrogen donor. ${ }^{33,42}$ However, to the best of our knowledge, the reduction of ketones with $3 \mathrm{~d}$ base metals and formic acid has not yet been reported. As with Ru-based systems, ${ }^{41}$ we performed the reaction under dilute conditions in order to prevent the decrease of ee over time (Figure 5a). Indeed, in the presence of a large excess of ${ }^{\mathrm{i}} \mathrm{PrOH}$, erosion of ee was less pronounced. Increased reaction temperature resulted in significantly reduced product ee (Figure $5 b$ ).

We hypothesized that use of a more sterically demanding ketone substrate would lead to improved ee's compared to acetophenone (Figure $5 \mathrm{c}$ and $\mathrm{d}$ ). Indeed, the ATH of isobutyrophenone under identical conditions results in quantitative production of $(R)$-2-methyl-1-phenylpropanol with $87 \%$ ee, albeit at a reduced reaction rate, i.e., $\sim 85 \%$ 
$\mathrm{TOF}^{0}$ obtained with acetophenone reduction at $60{ }^{\circ} \mathrm{C}$ with 1 mol \% 1-Cis.

\section{CONCLUSION}

In conclusion, we have synthesized and characterized a series of simple chiral manganese-diamine complexes which were evaluated for their catalytic performance in asymmetric transfer hydrogenation of acetophenones. Complexes 1-Cis and 1Trans are stereoselective ATH catalysts for the synthesis of enantio-enriched secondary alcohols in good to quantitative yields. We conducted a detailed theoretical and experimental mechanistic investigation including the first detailed kinetic study for the Mn-catalyzed ATH of ketones. Our ligand screening revealed that introduction of simple diamine ligands does not induce sufficient steric strain to facilitate high enantioselectivity. We however found that such strain cannot practically be applied on the described Mn complexes bearing $\mathrm{N}$-donors while concomitantly maintaining high catalytic activity. We demonstrated that different stereoisomeric precatalysts upon activation converge to shared intermediates and thus exhibit identical catalytic performance. This renders conventional approaches toward catalyst optimization unsuccessful and thus demands more thorough studies. Mechanistic insight and the recent applications of bidentate ligands containing a NHC group ${ }^{14,25}$ suggest that introduction of a strongly donating but small bidentate ligand could lead to highly active and selective second-generation $\mathrm{Mn}$ catalysts for ATH of ketones.

\section{ASSOCIATED CONTENT}

\section{S Supporting Information}

The Supporting Information is available free of charge on the ACS Publications website at DOI: 10.1021/acs.organomet.9b00457.

Experimental procedures and raw kinetic data (PDF)

Coordinates of optimized structures (XYZ)

\section{Accession Codes}

CCDC 1903883-1903885 contain the supplementary crystallographic data for this paper. These data can be obtained free of charge via www.ccdc.cam.ac.uk/data_request/cif, or by emailing data_request@ccdc.cam.ac.uk, or by contacting The Cambridge Crystallographic Data Centre, 12 Union Road, Cambridge CB2 1EZ, UK; fax: +44 1223336033.

\section{AUTHOR INFORMATION}

\section{Corresponding Author}

*E-mail: E.A.Pidko@tudelft.nl.

\section{ORCID $\odot$}

Robbert van Putten: 0000-0001-5074-6706

Georgy A. Filonenko: 0000-0001-8025-9968

Chong Liu: 0000-0003-0311-8744

Laurent Lefort: 0000-0003-2973-6540

Evgeny Pidko: 0000-0001-9242-9901

\section{Present Address}

${ }^{\perp}$ C.L.: Institute for Catalysis, Hokkaido University, N-21, W10, Sapporo, Japan.

\section{Author Contributions}

The manuscript was written through contributions of all authors. All authors have given approval to the final version of the manuscript.

\section{Notes}

The authors declare no competing financial interest.

\section{ACKNOWLEDGMENTS}

This project has been funded by the European Research Council (ERC) under the European Union's Horizon 2020 research and innovation programme (Grant Agreement No. 725686). We thank the students in our group Christophe Besnard and Joeri Benschop for their contributions to this work and the Ministry of Education and Science of the Russian Federation (Project 11.1706.2017/4.6) for partial support. The authors thank NWO Exact and Natural Sciences for providing access to the SurfSARA supercomputer facilities.

\section{REFERENCES}

(1) Bullock, R. M. Abundant Metals Give Precious Hydrogenation Performance. Science 2013, 342 (6162), 1054-1055.

(2) Valyaev, D. A.; Lavigne, G.; Lugan, N. Manganese organometallic compounds in homogeneous catalysis: Past, present, and prospects. Coord. Chem. Rev. 2016, 308 (2), 191-235.

(3) Filonenko, G. A.; van Putten, R.; Hensen, E. J. M.; Pidko, E. A. Catalytic (de)hydrogenation promoted by non-precious metals - Co, $\mathrm{Fe}$ and $\mathrm{Mn}$ : recent advances in an emerging field. Chem. Soc. Rev. 2018, 47 (4), 1459-1483.

(4) Reed-Berendt, B. G.; Polidano, K.; Morrill, L. C. Recent advances in homogeneous borrowing hydrogen catalysis using earthabundant first row transition metals. Org. Biomol. Chem. 2019, 17, 1595-1607.

(5) Garbe, M.; Junge, K.; Beller, M. Homogeneous Catalysis by Manganese-Based Pincer Complexes. Eur. J. Org. Chem. 2017, 2017 (30), 4344-4362.

(6) Kallmeier, F.; Kempe, R. Manganese Complexes for (De)Hydrogenation Catalysis: A Comparison to Cobalt and Iron Catalysts. Angew. Chem., Int. Ed. 2018, 57 (1), 46-60.

(7) Gorgas, N.; Kirchner, K. Isoelectronic Manganese and Iron Hydrogenation/Dehydrogenation Catalysts: Similarities and Divergences. Acc. Chem. Res. 2018, 51 (6), 1558-1569.

(8) Pritchard, J.; Filonenko, G. A.; van Putten, R.; Hensen, E. J. M.; Pidko, E. A. Heterogeneous and homogeneous catalysis for the hydrogenation of carboxylic acid derivatives: history, advances and future directions. Chem. Soc. Rev. 2015, 44 (11), 3808-3833.

(9) Zuo, W.; Lough, A. J.; Li, Y. F.; Morris, R. H. Amine(imine)diphosphine Iron Catalysts for Asymmetric Transfer Hydrogenation of Ketones and Imines. Science 2013, 342 (6162), 1080-1083.

(10) Bielinski, E. A.; Förster, M.; Zhang, Y.; Bernskoetter, W. H.; Hazari, N.; Holthausen, M. C. Base-Free Methanol Dehydrogenation Using a Pincer-Supported Iron Compound and Lewis Acid Cocatalyst. ACS Catal. 2015, 5 (4), 2404-2415.

(11) Bielinski, E. A.; Lagaditis, P. O.; Zhang, Y.; Mercado, B. Q.; Würtele, C.; Bernskoetter, W. H.; Hazari, N.; Schneider, S. Lewis Acid-Assisted Formic Acid Dehydrogenation Using a PincerSupported Iron Catalyst. J. Am. Chem. Soc. 2014, 136 (29), 1023410237.

(12) Fu, S.; Shao, Z.; Wang, Y.; Liu, Q. Manganese-Catalyzed Upgrading of Ethanol into 1-Butanol. J. Am. Chem. Soc. 2017, 139 (34), 11941-11948.

(13) Maji, B.; Barman, M. K. Recent Developments of Manganese Complexes for Catalytic Hydrogenation and Dehydrogenation Reactions. Synthesis 2017, 49 (15), 3377-3393.

(14) Buhaibeh, R.; Filippov, O. A.; Bruneau-Voisine, A.; Willot, J.; Duhayon, C.; Valyaev, D. A.; Lugan, N.; Canac, Y.; Sortais, J.-B. Phosphine-NHC Manganese Hydrogenation Catalyst Exhibiting a Non-Classical Metal-Ligand Cooperative $\mathrm{H} 2$ Activation Mode. Angew. Chem., Int. Ed. 2019, 58 (20), 6727-6731.

(15) Misal Castro, L. C.; Li, H.; Sortais, J.-B.; Darcel, C. When iron met phosphines: a happy marriage for reduction catalysis. Green Chem. 2015, 17 (4), 2283-2303. 
(16) Kallmeier, F.; Irrgang, T.; Dietel, T.; Kempe, R. Highly Active and Selective Manganese $\mathrm{C}=\mathrm{O}$ Bond Hydrogenation Catalysts: The Importance of the Multidentate Ligand, the Ancillary Ligands, and the Oxidation State. Angew. Chem., Int. Ed. 2016, 55 (39), 11806-11809.

(17) Dubey, A.; Nencini, L.; Fayzullin, R. R.; Nervi, C.; Khusnutdinova, J. R. Bio-Inspired $\mathrm{Mn}(\mathrm{I})$ Complexes for the Hydrogenation of $\mathrm{CO} 2$ to Formate and Formamide. ACS Catal. 2017, 7 (6), 3864-3868.

(18) Perez, M.; Elangovan, S.; Spannenberg, A.; Junge, K.; Beller, M. Molecularly Defined Manganese Pincer Complexes for Selective Transfer Hydrogenation of Ketones. ChemSusChem 2017, 10 (1), 83-86.

(19) Bruneau-Voisine, A.; Wang, D.; Dorcet, V.; Roisnel, T.; Darcel, C.; Sortais, J.-B. Transfer Hydrogenation of Carbonyl Derivatives Catalyzed by an Inexpensive Phosphine-Free Manganese Precatalyst. Org. Lett. 2017, 19 (13), 3656-3659.

(20) Martínez-Ferraté, O.; Werlé, C.; Franciò, G.; Leitner, W. Aminotriazole $\mathrm{Mn}(\mathrm{I})$ Complexes as Effective Catalysts for Transfer Hydrogenation of Ketones. ChemCatChem 2018, 10 (20), 45144518.

(21) Shvydkiy, N. V.; Vyhivskyi, O.; Nelyubina, Y.; Perekalin, D. Design of manganese phenol pi-complexes as Shvo-type catalysts for transfer hydrogenation of ketones. ChemCatChem 2019, 11 (6), $1602-1605$

(22) Ganguli, K.; Shee, S.; Panja, D.; Kundu, S. Cooperative Mn(I)complex catalyzed transfer hydrogenation of ketones and imines. Dalton Trans 2019, 48, 7358-7366.

(23) Dubey, A.; Rahaman, S. M. W.; Fayzullin, R. R.; Khusnutdinova, J. Transfer hydrogenation of carbonyl groups, imines and $\mathrm{N}$-heterocycles catalyzed by simple, bipyridine-based $\mathrm{MnI}$ complexes. ChemCatChem 2019, DOI: 10.1002/cctc.201900358.

(24) Wei, D.; Bruneau-Voisine, A.; Dubois, M.; Bastin, S.; Sortais, J.B. Manganese-Catalyzed Transfer Hydrogenation of Aldimines. ChemCatChem 2019, DOI: 10.1002/cctc.201900314.

(25) van Putten, R.; Benschop, J.; de Munck, V.; Weber, M.; Mueller, C.; Filonenko, G.; Pidko, E. A. Efficient and practical transfer hydrogenation of ketones catalyzed by a simple bidentate Mn-NHC complex. ChemCatChem 2019, DOI: 10.1002/cctc.201900882.

(26) Zirakzadeh, A.; de Aguiar, S. R. M. M.; Stöger, B.; Widhalm, M.; Kirchner, K. Enantioselective Transfer Hydrogenation of Ketones Catalyzed by a Manganese Complex Containing an Unsymmetrical Chiral PNP' Tridentate Ligand. ChemCatChem 2017, 9, 1744-1748.

(27) Widegren, M. B.; Harkness, G. J.; Slawin, A. M. Z.; Cordes, D. B.; Clarke, M. L. A Highly Active Manganese Catalyst for Enantioselective Ketone and Ester Hydrogenation. Angew. Chem., Int. Ed. 2017, 56, 5825-5828.

(28) Garbe, M.; Junge, K.; Walker, S.; Wei, Z.; Jiao, H.; Spannenberg, A.; Bachmann, S.; Scalone, M.; Beller, M. Manganese(I)-Catalyzed Enantioselective Hydrogenation of Ketones Using a Defined Chiral PNP Pincer Ligand. Angew. Chem., Int. Ed. 2017, 56 (37), 11237-11241.

(29) Schneekönig, J.; Junge, K.; Beller, M. Manganese Catalyzed Asymmetric Transfer Hydrogenation of Ketones Using Chiral Oxamide Ligands. Synlett 2019, 30 (04), 503-507.

(30) Demmans, K. Z.; Olson, M. E.; Morris, R. H. Asymmetric Transfer Hydrogenation of Ketones with Well-Defined Manganese(I) PNN and PNNP Complexes. Organometallics 2018, 37 (24), 46084618.

(31) Wang, D.; Bruneau-Voisine, A.; Sortais, J.-B. Practical (asymmetric) transfer hydrogenation of ketones catalyzed by manganese with (chiral) diamines ligands. Catal. Commun. 2018, 105, 31-36.

(32) Magano, J.; Dunetz, J. R. Large-Scale Carbonyl Reductions in the Pharmaceutical Industry. Org. Process Res. Dev. 2012, 16 (6), $1156-1184$.

(33) Wang, D.; Astruc, D. The Golden Age of Transfer Hydrogenation. Chem. Rev. 2015, 115 (13), 6621-6686.

(34) van Putten, R.; Uslamin, E. A.; Garbe, M.; Liu, C.; GonzalezDe-Castro, A.; Lutz, M.; Junge, K.; Hensen, E. J. M.; Beller, M.;
Lefort, L.; Pidko, E. A. Non-Pincer-Type Manganese Complexes as Efficient Catalysts for the Hydrogenation of Esters. Angew. Chem., Int. Ed. 2017, 56 (26), 7531-7534.

(35) Langer, R.; Diskin-Posner, Y.; Leitus, G.; Shimon, L. J. W.; BenDavid, Y.; Milstein, D. Low-Pressure Hydrogenation of Carbon Dioxide Catalyzed by an Iron Pincer Complex Exhibiting Noble Metal Activity. Angew. Chem., Int. Ed. 2011, 50 (42), 9948-9952.

(36) Frisch, M.; Trucks, G.; Schlegel, H.; Scuseria, G.; Robb, M.; Cheeseman, J.; Scalmani, G.; Barone, V.; Mennucci, B.; Petersson, G. Gaussian 09, revision D.01; Gaussian, Inc.: Wallingford, CT, 2009.

(37) Nguyen, D. H.; Trivelli, X.; Capet, F.; Paul, J.-F.; Dumeignil, F.; Gauvin, R. M. Manganese Pincer Complexes for the Base-Free, Acceptorless Dehydrogenative Coupling of Alcohols to Esters: Development, Scope, and Understanding. ACS Catal. 2017, 7 (3), 2022-2032.

(38) Wisman, R. V.; de Vries, J. G.; Deelman, B.-J.; Heeres, H. J. Kinetic Studies on the Asymmetric Transfer Hydrogenation of Acetophenone Using a Homogeneous Ruthenium Catalyst with a Chiral Amino-Alcohol Ligand. Org. Process Res. Dev. 2006, 10 (3), 423-429.

(39) Swiegers, G. F. Mechanical Catalysis: Methods of Enzymatic, Homogeneous, and Heterogeneous Catalysis; John Wiley \& Sons, Inc.: 2008.

(40) Liu, C.; van Putten, R.; Kulyaev, P. O.; Filonenko, G. A.; Pidko, E. A. Computational insights into the catalytic role of the base promoters in ester hydrogenation with homogeneous non-pincerbased Mn-P,N catalyst. J. Catal. 2018, 363, 136-143.

(41) Hashiguchi, S.; Fujii, A.; Takehara, J.; Ikariya, T.; Noyori, R. Asymmetric Transfer Hydrogenation of Aromatic Ketones Catalyzed by Chiral Ruthenium(II) Complexes. J. Am. Chem. Soc. 1995, 117 (28), 7562-7563.

(42) Fujii, A.; Hashiguchi, S.; Uematsu, N.; Ikariya, T.; Noyori, R. Ruthenium(II)-Catalyzed Asymmetric Transfer Hydrogenation of Ketones Using a Formic Acid-Triethylamine Mixture. J. Am. Chem. Soc. 1996, 118 (10), 2521-2522. 